Article

\title{
Health-Related Quality of Life in Older Adults: Its Association with Health Literacy, Self-Efficacy, Social Support, and Health-Promoting Behavior
}

\author{
Myung Kyung Lee ${ }^{1}$ and Jihyun $\mathrm{Oh}^{2, *}$ \\ 1 College of Nursing, Research Institute of Nursing Science, Kyungpook National University, \\ Daegu 41944, Korea; mlee@knu.ac.kr \\ 2 Department of Nursing, Daejeon University, Daejeon 34520, Korea \\ * Correspondence: jihy0123@dju.kr
}

Received: 1 October 2020; Accepted: 13 October 2020; Published: 16 October 2020

check for updates

\begin{abstract}
This cross-sectional study aimed to explore the relationships among sociodemographics, health literacy, self-efficacy, social support, health-promoting behavior, and health-related quality of life (HRQOL) in older adults. A total of 240 older adults aged $>65$ years were recruited from three community senior welfare centers in South Korea. Standardized self-administered questionnaires measuring sociodemographic characteristics, health literacy, social support, self-efficacy, health-promoting behavior, and health-related quality of life were distributed to older adults. Multiple regression analyses with stepwise selection was used to determine the factors affecting health-related quality of life. Factors affecting a higher physical component score of HRQOL were a higher comprehension level of and numeracy in health literacy, physical health-promoting behavior, perceived emotional-informational support, and a lesser number of comorbidities. Factors affecting a higher mental component score of HRQOL were a higher comprehension level of and numeracy in health literacy, self-efficacy, physical health-promoting behavior, perceived emotional-informational support, and a lesser number of comorbidities. To improve HRQOL among older adults, nursing interventions are required to measure health literacy, empower physical health-promoting behavior and self-efficacy, and enhance emotional-informational support from family or other resources.
\end{abstract}

Keywords: health literacy; self-efficacy; social support; health-promoting behavior; quality of life

\section{Introduction}

The elderly group is the fastest growing segment of the population, predicted to rise from $15.7 \%$ in 2020 to $25.0 \%$ in 2030 [1]. Cognitive and psychosocial factors have been shown to determine survival, use of medical services, health-promoting behavior, and health-related quality of life (HRQOL) in older individuals [2-5]. As the key cognitive and psychosocial factors, health literacy, self-efficacy, social support, and health-promoting behavior are considered in this older age group.

Health literacy (HL), defined as the capacity to access, understand, evaluate, and apply basic health information to promote, maintain, and improve one's health during the course of life [6], plays a significant role in managing multiple chronic diseases in older adults. In South Korea, over $90 \%$ of adults aged $>70$ years have low literacy skills with a low educational level, defined as having low HL $[7,8]$. Low HL is associated with negative health outcomes, including low HRQOL in older adults [4,9], poor use of healthcare in older adults [10], misunderstanding medical instructions, unhealthy behaviors in older adults [11], poor medication adherence in older adults with asthma [12], and poorer self-reported health in the elderly [9].

Self-efficacy is a useful indicator of general adaptational outcomes [13]. Psychological factors play a key role in the adjustment of older adults to chronic disease. Self-efficacy refers to an individual's belief 
in his or her capacity to execute behaviors necessary to produce specific performance attainments [14]. A person with high self-efficacy can have a more active life course [15], and the active approach to life may have a positive effect on an individual's QOL. Individuals with high, generalized self-efficacy are more likely to benefit from health education programs than those with low self-efficacy in healthy older people [16]. Previous studies found that general self-efficacy and specific self-efficacy for specific disease self-management (e.g., diabetes or stoma management) is correlated with a positive QOL in older adults or older patients $[3,17,18]$ and improved compliance with self-care activities in older patients [19]. Moreover, social support is the perception and experience that one is valued, respected, cared for, and loved by others who are present in one's life [20]. Social support has been recognized as one of the most important factors of QOL in older adults [21]. It has a significant effect on the QOL of the older adults [18,21] and chronically ill patients [2]. Thus, the provision of social support from family, healthcare providers, friends, and peer group has been suggested to be employed in the intervention programs for the older adults, chronically ill older patients, or vulnerable older adults as an important strategy in the intervention for improving QOL [22,23].

Moreover, health-promoting lifestyles are the primary adjustable strategy focusing on health promotion through lifestyle, which is vital to the quality of life. A health-promoting lifestyle includes activities to maintain or improve one's health, including physical, social, and emotional well-being, and to affect healthy aging [24]. A healthy lifestyle leads to better health outcomes of the remaining years of the elderly individual [25]. Previous studies demonstrated that a healthy lifestyle not only reflects a subjective health status but also decreases the development of chronic disease and mitigates chronic medical conditions in older patients $[2,26]$.

As mentioned above, the importance of HL, self-efficacy, social support, and health-promoting behavior for successful aging, which significantly affect older adults' QOL, is well documented $[2-5,22,27,28]$. These are modifiable variables that can affect health status and QOL.

Some studies demonstrated that QOL is not significantly correlated with HL [29-31], self-efficacy [26], or health-promoting behavior [32,33] in older adults. In contrast, other studies showed that higher levels of HL, self-efficacy, social support, or health-promoting behavior in older adults were associated with higher QOL scores [2-5,20,24-26,34]. Previous studies indicated that results from the studies of the relationships of HL, self-efficacy, social support, and health-promoting behavior to HRQOL have substantially less consistency. Repeated studies on these factors affecting QOL are needed. Identifying the research gap in cognitive and psychosocial factors associated with HRQOL is essential for the development of health intervention in nursing practice for older adults.

According to the above-described background, the research question of this study was whether health literacy, self-efficacy, health-promoting behavior, and social support perceived by older adults were associated with their health-related quality of life, and to find answers to the research question, a cross-sectional design survey was conducted. Our hypothesis was that the higher health literacy, self-efficacy, health-promoting behavior, and social support perceived by older adults has a positive effect on their health-related quality of life. Therefore, this study aimed to determine the relationships among health literacy, self-efficacy, social support, health-promoting behavior, and HRQOL in older adults and to investigate their effects on HRQOL.

\section{Materials and Methods}

A cross-sectional survey was conducted at three community senior welfare centers in the central district of South Korea from 27 November 2016 to 5 January 2017. Participants were recruited through convenience sampling when they visited community centers. The inclusion criteria were as follows: (1) age of at least 65 years; (2) no cognitive impairment detected during Mini-Cog instrument screening [35]; and (3) ability to communicate and complete a self-administered questionnaire. Questionnaires were directly distributed only to older adults who had provided written consent after being informed about the purpose of the study. The survey was distributed to 249 older adults, of which 240 questionnaires were returned (response rate: 96.3\%). In principle, the participants 
answered the questionnaire by themselves, and if they asked for help or a question while answering the questionnaire, the research staff provided support. In the case of the subjects' vision problems, the researcher staff read the questions of the study and marked the subjects' answers.

\subsection{Measurement}

\subsubsection{Health Literacy}

The short form of the Korean Health Literacy Scale (S-KHLS), developed by Lee and Kang [36], was used to measure HL. The S-KHLS consists of 12 items, with five questions on health-related terms and seven questions on comprehension and numeracy. The Cronbach's $\alpha$ for this scale in this study was 0.80 .

\subsubsection{Social Support}

Social support was measured using the 19-item Medical Outcome Study Social Support Survey (MOS-SSS), developed by Sherbourne and Stewart [37]. The items measure the four subscales of social support using a 5-point Likert response scale, ranging from 1 (none of the time) to 5 (all of the time). The MOS-SSS is designed to assess four different dimensions of social support: emotional-informational, tangible support, affectionate support, and positive social interaction. The total score ranges from 0 to 100 , in which higher scores indicate higher social support and lower risk of isolation. The Cronbach's $\alpha$ for this scale in this study was 0.96 .

\subsubsection{Self-Efficacy}

The self-efficacy scale was developed by Schwarzer and Jerusalem [15]. This scale consists of 10 items using a 4-point Likert scale, ranging from 1 (not at all true) to 4 (completely true). The total score ranges from 10 to 40, with a higher score indicating higher self-efficacy. The Cronbach's $\alpha$ in the current study was 0.89 , suggesting acceptable internal consistency.

\subsubsection{Health-Promoting Behavior}

The Health Promotion Lifestyle Profile II, developed by Walker et al. [38] and modified by Lee [21], was used to measure the health-promoting behavior. The scale consisted of 13 items that included three dimensions of health-promoting behavior: physical area (five items), social area (five items), and emotional area (three items). The scale was scored on a 5-point Likert scale, with responses ranging from 1 (strongly disagree) to 5 (strongly agree). The total score ranges from 13 to 65 , with higher scores representing a higher level of health-promoting behavior. The Cronbach's $\alpha$ for this scale in this study was 0.85 .

\subsubsection{Health-Related Quality of Life}

This scale was assessed using the Medical Outcomes Study Short-Form Health Survey-12 (SF-12) [39]. The SF-12 is an abbreviated version of the original SF-36. This instrument contains 12 items, which measure two components of QOL: Physical Component Summary (PCS-12) and Mental Component Summary (MCS-12). The scores range from 0 to 100, and a higher score indicates better HRQOL. The Cronbach's $\alpha$ for this scale in this study was 0.86 .

\subsection{Ethical Considerations}

The study was approved by the University Institutional Review Board (number: 1040647-201601-HR003-03). All participants were informed about the aims and plan of the study, and written consent was obtained from all study participants prior to their participation. Moreover, this study complied with the ethical guidelines delineated in the Declaration of Helsinki. 


\subsection{Statistical Analyses}

Sociodemographic characteristics, HL, perceived social support, self-efficacy, health-promoting behavior, and HRQOL were analyzed using descriptive statistics. For the univariate analyses, independent $t$-test, one-way analysis of variance (ANOVA), and Scheffé's post hoc test were performed to compare the HRQOL according to sociodemographic parameters. Correlations among $\mathrm{HL}$, social support, self-efficacy, and health-promoting behavior were identified using Pearson's correlation coefficient.

We performed multiple regression analyses with stepwise selection to determine the factors affecting HRQOL, in which we set a regression model with the variables that were significantly associated with HRQOL in the univariate analyses (i.e., independent $t$-test, ANOVA, Pearson's correlation). All statistical analyses were two sided; $p$-values $<0.05$ were considered statistically significant. All statistical analyses were performed using IBM SPSS Statistics software Version 22.0 (IBM Corp., Armonk, NY, USA).

\section{Results}

\subsection{Participants' General Characteristics and Differences}

Of 249 individuals, 240 fully participated in the study (response rate, 96.3\%) (Table 1). The mean age of the participants was 75.6 years (standard deviation $(\mathrm{SD})=6.3$ ), ranging from 65 to 95 years. More than half of the participants were male (57.9\%), 65.0\% were married, and the proportion of those who did not receive education or elementary school was $43.3 \%$. A majority of participants $(69.6 \%)$ were affiliated with a religious group. More than half of the participants (58.8\%) reported their economic status as above mid-level, and $46.7 \%$ had at least one comorbidity. Regarding the PCS scores according to participants' general characteristics, there was a significant difference in age group $(t=2.652, p=0.008)$, marital status $(F=3.92, p=0.021)$, economic status $(t=2.60, p=0.010)$, and number of comorbidities ( $F=13.82, p<0.001)$. Regarding the MCS scores according to participants' general characteristics, there was a significant difference in economic status $(t=2.76, p=0.006)$ and number of comorbidities $(\mathrm{F}=6.22, p=0.002)$. The results of the post hoc tests with ANOVA showed that older adults who had more than one comorbidity showed significantly lower PCS scores than those without comorbidities. Moreover, older adults who had more than one comorbidity showed significantly lower MCS scores than those without comorbidities. 
Table 1. Descriptive statistics of participants' general characteristics and differences $(N=240)$.

\begin{tabular}{|c|c|c|c|c|c|c|c|}
\hline \multirow{2}{*}{ Characteristics } & \multirow{2}{*}{ Mean } & \multirow{2}{*}{ Range } & \multirow{2}{*}{$n(\%)$} & \multicolumn{2}{|r|}{ PCS-12 } & \multicolumn{2}{|c|}{ MCS-12 } \\
\hline & & & & Mean & t or F $(p)$ Scheffé & Mean & t or F $(p)$ Scheffé \\
\hline Age (year) & $75.6(6.3)$ & $65-95$ & & & & & \\
\hline$\geq 65,<75$ & & & $108(45.0)$ & $64.4(14.9)$ & & $78.4(15.9)$ & \\
\hline$\geq 75,<95$ & & & $132(55.0)$ & $59.1(15.9)$ & $2.652(0.008)$ & $74.9(15.2)$ & $1.731(0.085)$ \\
\hline \multicolumn{8}{|l|}{ Sex } \\
\hline Male & & & 139 (57.9) & $60.3(15.9)$ & & 76.7 (75.1) & \\
\hline Female & & & $101(42.1)$ & $63.1(15.2)$ & $-1.34(0.182)$ & $76.2(16.4)$ & $0.23(0.822)$ \\
\hline \multicolumn{8}{|l|}{ Education } \\
\hline No education or elementary school & & & $104(43.3)$ & $59.3(15.1)$ & & $75.2(15.7)$ & \\
\hline Middle school & & & $51(21.3)$ & $62.4(17.5)$ & & $76.9(16.8)$ & \\
\hline$\geq$ High school & & & $85(35.4)$ & $63.6(15.0)$ & $1.84(0.161)$ & $77.8(14.9)$ & $0.64(0.530)$ \\
\hline \multicolumn{8}{|l|}{ Marital status } \\
\hline Single & & & $17(7.1)$ & $55.3(20.9)$ & & $70.2(22.4)$ & \\
\hline Married & & & $156(65.0)$ & $63.5(14.5)$ & & $77.3(15.1)$ & \\
\hline Divorced/Widowed & & & $67(27.9)$ & $58.5(16.1)$ & $3.92(0.021)$ & $76.2(14.7)$ & $1.60(0.203)$ \\
\hline \multicolumn{8}{|l|}{ Religion } \\
\hline Yes & & & $167(69.6)$ & $60.8(15.9)$ & & $75.7(15.9)$ & \\
\hline No & & & $73(30.5)$ & $63.0(15.1)$ & $-1.00(0.319)$ & $78.3(15.0)$ & $-1.18(0.241)$ \\
\hline \multicolumn{8}{|l|}{ Economic status } \\
\hline$\geq$ Middle & & & $141(58.8)$ & $63.7(14.7)$ & & $78.8(15.2)$ & \\
\hline Low & & & $99(41.3)$ & $58.6(16.6)$ & $2.60(0.010)$ & $73.2(15.7)$ & $2.76(0.006)$ \\
\hline \multicolumn{8}{|l|}{ Number of comorbidities } \\
\hline 0 & & & $75(31.3)$ & $68.6(14.6)$ & & $81.6(14.7)$ & \\
\hline 1 & & & $112(46.7)$ & $59.6(14.9)$ & & $74.5(15.1)$ & \\
\hline$\geq 2$ & & & $53(22.1)$ & $55.4(15.2)$ & $13.82(<0.001) \mathrm{a}>\mathrm{b}, \mathrm{c}$ & $73.4(16.5)$ & $6.22(0.002) a>b, c$ \\
\hline
\end{tabular}

SD, standard deviation; SF-12, Short-Form Health Survey; PCS, Physical Component Summary; MCS, Mental Component Summary; a, No comorbidity; b, 1 comorbidity; c, $\geq 2$ comorbidities. 


\subsection{Scores for HL, Social Support, Self-Efficacy, Health-Promoting Behavior, and HRQOL}

As shown in Table 2, the mean comprehension and numeracy scores for HL was 5.0 out of a maximum possible score of 7 , and the mean health-related term score for HL was 4.3 out of a maximum possible score of 5 . Of the social support subscales, the scores for tangible support, affectionate support, positive social interaction, and emotional-informational support were $14.8(\mathrm{SD}=4.7), 11.5(\mathrm{SD}=3.4)$, $14.9(\mathrm{SD}=4.5)$, and $30.0(\mathrm{SD}=5.8)$, respectively. The mean score for self-efficacy was $30.8(\mathrm{SD}=5.8)$. Of the health-promoting behavior subscales, the physical area showed the highest score $(\mathrm{M}=21.4$, $\mathrm{SD}=3.6)$, followed by the social area $(\mathrm{M}=18.0, \mathrm{SD}=4.5)$, and the emotional area showed the lowest score $(\mathrm{M}=11.7, \mathrm{SD}=2.7)$. The mean HRQOL score for physical health was $63.6(\mathrm{SD}=7.8)$, whereas that for mental health was $67.8(\mathrm{SD}=10.8)$.

Table 2. Scores for health literacy, social support, self-efficacy, health-promoting behavior, and health-related quality of life (HRQOL) $(N=240)$.

\begin{tabular}{ccc}
\hline Variables & Range & Mean [SD] \\
\hline Health literacy & & \\
Health-related terms & $0-5$ & $4.3(1.0)$ \\
Comprehension and numeracy & $0-7$ & $5.0(1.6)$ \\
Social support & & \\
Tangible & $4-20$ & $14.8(4.7)$ \\
Affectionate & $3-15$ & $11.5(3.4)$ \\
Positive social interaction & $4-20$ & $14.9(4.5)$ \\
Emotional-informational & $8-40$ & $30.0(8.2)$ \\
Self-efficacy & $10-40$ & $30.8(5.8)$ \\
Health-promoting behavior & & \\
Physical area & $5-25$ & $21.4(3.6)$ \\
Social area & $5-25$ & $18.0(4.5)$ \\
Emotional area & $3-15$ & $11.7(2.7)$ \\
HRQOL (SF-12) & & \\
Physical health (PCS-12) & $36.7-90.0$ & $63.6(7.8)$ \\
Mental health (MCS-12) & $37.5-97.5$ & $67.8(10.8)$ \\
\hline
\end{tabular}

SD, standard deviation; HRQOL, health-related quality of life; SF-12, Short-Form Health Survey.

\subsection{Correlations between HRQOL and HL, Social Support, and Health-Promoting Behavior}

The physical component of HRQOL was significantly positively correlated with comprehension and numeracy subscale of HL $(r=0.16, p=0.011)$, all subscales of social support (tangible support, $r=0.27, p<0.001$; affectionate support, $r=0.20, p=0.002$; positive social interaction, $r=0.25, p<0.001$; emotional-informational support, $r=0.30, p<0.001)$, self-efficacy $(r=0.23, p<0.001)$, and all subscales of health-promoting behavior (physical area, $r=0.28, p<0.001$; social area, $r=0.21, p<0.001$; emotional area, $r=0.18, p=0.004$ ).

The mental component of HRQOL was significantly positively correlated with all subscales of HL (health-related terms, $r=0.13, p=0.047$; comprehension and numeracy, $r=0.20, p=0.002$ ), all subscales of social support (tangible support, $r=0.24, p<0.001$; affectionate support, $r=0.31, p<0.001$; positive social interaction, $r=0.29, p<0.001$; emotional-informational support, $r=0.36, p<0.001$ ), self-efficacy $(r=0.30, p<0.001$ ), and all subscales of health-promoting behavior (physical area, $r=0.23, p<0.001$; social area, $r=0.17, p<0.001$; emotional area, $r=0.18, p=0.006$ ) (Table 3). 
Table 3. Correlations among variables $(N=240)$

\begin{tabular}{|c|c|c|c|c|c|c|c|c|c|c|c|c|}
\hline \multirow{3}{*}{ Variables } & \multicolumn{12}{|c|}{$\mathbf{r}(p)$} \\
\hline & \multicolumn{2}{|c|}{ Health Literacy } & \multicolumn{4}{|c|}{ Social Support } & \multicolumn{2}{|c|}{ Self-Efficacy } & \multicolumn{2}{|l|}{ НРB } & \multicolumn{2}{|c|}{ SF-12 } \\
\hline & 1 & 2 & 3 & 4 & 5 & 6 & 7 & 8 & 9 & 10 & 11 & 12 \\
\hline 1. Health-related terms & - & & & & & & & & & & & \\
\hline 2. Comprehension and numeracy & $\begin{array}{c}0.30 \\
(<0.001)\end{array}$ & - & & & & & & & & & & \\
\hline 3. Tangible & $\begin{array}{c}0.06 \\
(0.380)\end{array}$ & $\begin{array}{c}0.05 \\
(0.479)\end{array}$ & - & & & & & & & & & \\
\hline 4. Affectionate & $\begin{array}{c}0.04 \\
(0.563)\end{array}$ & $\begin{array}{c}0.10 \\
(0.131)\end{array}$ & $\begin{array}{c}0.71 \\
(<0.001)\end{array}$ & - & & & & & & & & \\
\hline 5. Positive social interaction & $\begin{array}{c}0.05 \\
(0.427)\end{array}$ & $\begin{array}{c}0.09 \\
(0.151)\end{array}$ & $\begin{array}{c}0.76 \\
(<0.001)\end{array}$ & $\begin{array}{c}0.85 \\
(<0.001)\end{array}$ & - & & & & & & & \\
\hline 6. Emotional-informational & $\begin{array}{c}0.08 \\
(0.200)\end{array}$ & $\begin{array}{c}0.14 \\
(0.026)\end{array}$ & $\begin{array}{c}0.74 \\
(<0.001)\end{array}$ & $\begin{array}{c}0.85 \\
(<0.001)\end{array}$ & $\begin{array}{c}0.83 \\
(<0.001)\end{array}$ & - & & & & & & \\
\hline 7. Self-efficacy & $\begin{array}{c}0.03 \\
(0.698)\end{array}$ & $\begin{array}{l}-0.13 \\
(0.040)\end{array}$ & $\begin{array}{c}0.17 \\
(0.008)\end{array}$ & $\begin{array}{c}0.27 \\
(<0.001)\end{array}$ & $\begin{array}{c}0.21 \\
(<0.001)\end{array}$ & $\begin{array}{c}0.32 \\
(<0.001)\end{array}$ & - & & & & & \\
\hline 8. Physical area & $\begin{array}{c}0.05 \\
(0.428)\end{array}$ & $\begin{array}{l}-0.003 \\
(0.967)\end{array}$ & $\begin{array}{c}0.06 \\
(0.337)\end{array}$ & $\begin{array}{c}0.07 \\
(0.316)\end{array}$ & $\begin{array}{c}0.07 \\
(0.316)\end{array}$ & $\begin{array}{c}0.15 \\
(0.023)\end{array}$ & $\begin{array}{c}0.34 \\
(<0.001)\end{array}$ & - & & & & \\
\hline 9. Social area & $\begin{array}{c}0.05 \\
(0.447)\end{array}$ & $\begin{array}{l}-0.06 \\
(0.375)\end{array}$ & $\begin{array}{c}0.19 \\
(0.003)\end{array}$ & $\begin{array}{c}0.25 \\
(<0.001)\end{array}$ & $\begin{array}{c}0.29 \\
(<0.001)\end{array}$ & $\begin{array}{c}0.29 \\
(<0.001)\end{array}$ & $\begin{array}{c}0.30 \\
(<0.001)\end{array}$ & $\begin{array}{c}0.44 \\
(<0.001)\end{array}$ & - & & & \\
\hline 10. Emotional area & $\begin{array}{c}0.07 \\
(0.285)\end{array}$ & $\begin{array}{c}-0.07 \\
(0.273)\end{array}$ & $\begin{array}{c}0.13 \\
(0.052)\end{array}$ & $\begin{array}{c}0.14 \\
(0.027)\end{array}$ & $\begin{array}{c}0.09 \\
(0.151)\end{array}$ & $\begin{array}{c}0.18 \\
(0.005)\end{array}$ & $\begin{array}{c}0.19 \\
(0.004)\end{array}$ & $\begin{array}{c}0.39 \\
(<0.001)\end{array}$ & $\begin{array}{c}0.28 \\
(<0.001)\end{array}$ & - & & \\
\hline 11. PCS & $\begin{array}{c}0.05 \\
(0.428)\end{array}$ & $\begin{array}{c}0.16 \\
(0.011)\end{array}$ & $\begin{array}{c}0.27 \\
(<0.001)\end{array}$ & $\begin{array}{c}0.20 \\
(0.002)\end{array}$ & $\begin{array}{c}0.25 \\
(<0.001)\end{array}$ & $\begin{array}{c}0.30 \\
(<0.001)\end{array}$ & $\begin{array}{c}0.23 \\
(<0.001)\end{array}$ & $\begin{array}{c}0.28 \\
(<0.001)\end{array}$ & $\begin{array}{c}0.21 \\
(<0.001)\end{array}$ & $\begin{array}{c}0.18 \\
(0.004)\end{array}$ & - & \\
\hline 12. MCS & $\begin{array}{c}0.13 \\
(0.047)\end{array}$ & $\begin{array}{c}0.20 \\
(0.002)\end{array}$ & $\begin{array}{c}0.24 \\
(<0.001)\end{array}$ & $\begin{array}{c}0.31 \\
(<0.001)\end{array}$ & $\begin{array}{c}0.29 \\
(<0.001)\end{array}$ & $\begin{array}{c}0.36 \\
(<0.001)\end{array}$ & $\begin{array}{c}0.30 \\
(<0.001)\end{array}$ & $\begin{array}{c}0.23 \\
(<0.001)\end{array}$ & $\begin{array}{c}0.17 \\
(<0.001)\end{array}$ & $\begin{array}{c}0.18 \\
(0.006)\end{array}$ & $\begin{array}{c}0.64 \\
(<0.001)\end{array}$ & - \\
\hline
\end{tabular}

HL, health literacy; HPB, health-promoting behavior; HRQOL, health-related quality of life; SF-12, Short-Form Health Survey; 1, health-related terms; 2, comprehension and numeracy; 3, tangible; 4, affectionate; 5, positive social interaction; 6, emotional-informational; 7, self-efficacy; 8, physical area; 9 , social area; 10,emotional area; 11, PCS, Physical Component Summary; 12 , MCS, Mental Component Summary. 


\subsection{Factors Affecting HRQOL}

Factors affecting a higher physical component score of HRQOL were higher comprehension and numeracy of HL ( $\beta=0.40, p=0.022)$, physical health-promoting behavior $(\beta=0.30, p<0.001)$, perceived emotional-informational support ( $\beta=0.11, p=0.001)$, and a lesser number of comorbidities ( $\beta=-1.66, p<0.001)$. These factors explained $21 \%$ of the total variance of the physical component of HRQOL.

Factors affecting a higher mental component score of HRQOL were higher comprehension of and numeracy in HL $(\beta=0.59, p=0.001)$, self-efficacy $(\beta=0.16, p=0.002)$, physical area $(\beta=0.16, p=0.040)$, perceived emotional-informational support $(\beta=0.13, p=0.001)$, and less number of comorbidities ( $\beta=-0.78, p=0.004)$. These factors explained $21 \%$ of the total variance of mental component of HRQOL (Table 4). The results showed that higher health literacy, self-efficacy, health-promoting behavior, and social support had a positive influence on older adults' HRQOL, and our hypothesis was accepted.

Table 4. Results of the stepwise multiple regression analysis for HRQOL $(N=240)$.

\begin{tabular}{ccccccc}
\hline \multirow{2}{*}{ Variable } & \multicolumn{3}{c}{ PCS } & \multicolumn{3}{c}{ MCS } \\
\cline { 2 - 7 } & $\boldsymbol{\beta}$ (SE) & $\boldsymbol{t}$ & $\boldsymbol{p}$ & $\boldsymbol{\beta}$ (SE) & $\boldsymbol{t}$ & $\boldsymbol{p}$ \\
\hline Constant & $8.27(2.03)$ & 4.08 & $<0.001$ & $8.49(2.24)$ & 4.08 & $<0.001$ \\
Reading comprehension and numeracy & $0.40(0.17)$ & 2.31 & 0.022 & $0.59(0.18)$ & 3.34 & 0.001 \\
Self-efficacy & - & - & - & $0.16(0.05)$ & 3.09 & 0.002 \\
Physical area & $0.30(0.08)$ & 3.92 & $<0.001$ & $0.16(0.08)$ & 2.07 & 0.040 \\
Emotional-informational & $0.11(0.03)$ & 3.28 & 0.001 & $0.13(0.03)$ & 3.48 & 0.001 \\
Number of comorbidities & $-1.66(0.38)$ & -4.37 & $<0.001$ & $-0.78(0.38)$ & -2.06 & 0.004 \\
\hline Adjusted R $\mathrm{R}^{2}$ & 0.212 & \multicolumn{5}{c}{0.216} \\
\hline
\end{tabular}

HRQOL, health-related quality of life; PCS, Physical Component Summary; MCS, Mental Component Summary; $\mathrm{SE}$, standard error.

\section{Discussion}

The primary aim of the current study was to examine the factors affecting the HRQOL of older adults. Five variables were found to be significantly associated with HRQOL. Our results suggest that reading comprehension of and numeracy in HL, health-promoting behavior in the physical area, and emotional-informational support were significantly associated with the physical and mental components of HRQOL. Self-efficacy was also associated with the mental component of HRQOL. Furthermore, the number of comorbidities was associated with the mental and physical components of HRQOL. Our findings confirmed the results of previous studies.

In this study, the mean scores for MCS and PCS of HRQOL were 63.6 (7.8) and 67.8 (10.8) out of 100 points, respectively. The mean scores of HRQOL within our sample were considerably higher than the mean scores of MCS and PCS of elderly patients hospitalized for cardiovascular disease [40] and long-term dialysis patients [41]. This finding suggested that with the progression of the chronic diseases, health intervention should include different chronic disease programs to manage chronic conditions and strengthen health status.

The present findings are consistent with those of previous studies, suggesting that HL had a positive influence on HRQOL $[30,42]$. However, inadequate reading comprehension and numeracy skills can inhibit a patient's ability to attend appointment schedules with their clinicians and follow the prescription instructions correctly [43]. Misunderstanding medication labels and health messages is related to a higher adverse drug reaction and has been repeatedly found to be negatively associated with health outcomes [44,45]. With age, older individuals may have difficulty in performing complex cognitive tasks, and this could have resulted in poor HL, which may be related to poor health outcomes [46]. The results of this study support the findings of previous studies $[47,48]$ that good HL results in better HRQOL. 
The expected association between self-efficacy and the mental component of HRQOL was confirmed. This finding is in accordance with those of former studies, which indicated that greater self-efficacy was more strongly related to positive HRQOL of older adults $[17,18,49,50]$. Specific self-efficacy and general self-efficacy predicted global HRQOL. Specific self-efficacy on diabetes management (a patient's ability and confidence to effectively manage diabetes [51]), pain management [50,52,53], or stoma management [17] may be useful in improving HRQOL in this population. Moreover, general self-efficacy is important and independently correlated with HRQOL in older adults [3,18,49]. Our study specifically showed positive association between general self-efficacy and the mental health component of HRQOL in older adults. Self-efficacy, which refers to a patient's confidence in their ability to successfully achieve desired behavioral outcomes, is consistent with taking control and self-advocacy [14]. Bandura (1999) indicated that self-efficacy determines whether individuals think of their emotional well-being in self-aiding or self-debilitating ways [14]. One previous study suggested that individuals with high self-efficacy have less health-related stress [54]. Another study indicated that higher self-efficacy is associated with positive emotions and optimism [55], which may also partially explain the positive impact of self-efficacy on the mental component of HRQOL. Older individuals with higher self-efficacy can gain an increased sense of confidence in their ability to control and manage symptoms associated with chronic disease, long-term adherence in managing their disease [56], and better coping skills with a disease [57], which significantly enhance HRQOL. This study suggested that incorporating the concept of self-efficacy when instructing older adults about healthcare and management could help improve their chances of attaining a higher HRQOL perception. Consequently, older adults' beliefs regarding self-efficacy can affect their mental QOL. Hence, older individuals who aim to take responsibility for their self-care and believe that they have the skills in the desired care behavior have better mental QOL.

Similar to those of previous studies [2,28,58], our findings demonstrate a positive correlation between health-promoting behaviors and HRQOL in older adults. Among all health-promoting behaviors, the physical area was the only predictive factor for HRQOL. Age-related physical changes affect physical functions in older adults. With advancing age, health-promoting behaviors reduce the risk of adverse health outcomes. Specifically, we found that engaging in more physical health-promoting behaviors (i.e., regular and adequate levels of physical activity, adequate sleep, rest and relaxation, a balanced and healthy diet, and regular walking) have a greater impact on HRQOL.

Our findings support a positive relationship between emotional-informational support and HRQOL as described in former studies, indicating that social support is more strongly related to a higher HRQOL in older adults [18,21,22,28,34], older individuals with stoma [17], and older individuals with chronic disease [2,27,35,38,59]. The use of peer support programs (volunteer visits with clients) enforcing emotional-informational support significantly increased the levels of well-being among highly vulnerable, low-income older adults [23]. In older adults without impaired mobility who are not institutionalized and who live in a community, the main sources of perceived social support were family members and significant others [22,59-61] and friendship networks [62]. Strong family support was associated with better mental and physical HRQOL in older patients with multiple chronic conditions [59], and a strong friendship network was positively associated with physical HRQOL [59,63]. The protective and nursing role of the family toward their older members in need is typical of collectivist cultures, such as in South Korea, in which individuals maintain strong relationships with their families for life [64]. Thus, emotional-informational support from family members contributes indirectly to improved chronic disease-related outcomes and reduced psychological distress [65]. Moreover, the emotional-informational support from friends or other resources may reduce the physical impact of disease and lead to positive effects on the physical and mental components of HRQOL.

Older individuals with more comorbidities presented worse mental and physical HRQOL in our study, which is consistent with the results of previous studies $[59,66,67]$. Older adults with comorbidities are more prone to developing physical and psychological limitations. These results highlight the importance of assessing chronic diseases when caring for older adults. 


\subsection{Implication for Nursing Practice}

These findings indicated that HL and physical health-promoting behaviors are significant factors in improving the physical and mental components of HRQOL in older adults. The present study suggests that self-efficacy may be a crucial consideration when managing chronic disease and achieving a healthy lifestyle. Considering these results, to enhance HRQOL, nurses should take on a significant role in measuring HL and empowering physical health behaviors in older adults who have at least one chronic health condition by applying for health-promoting programs.

In clinical practice, nurses must plan and execute age-appropriate teaching strategies for the elderly by using familiar examples to promote health literacy. Healthcare providers, including nurses or nurse managers, must provide considerable effort to provide the elderly with health education and health information to improve their quality of living.

\subsection{Limitations}

This study has several limitations. First, the sample of the study was a convenience sample of community-dwelling older adults. In addition, recruiting from only one rural area in South Korea may limit the generalizability of the results to other countries. Second, HL, perceived social support, self-efficacy, health-promoting behavior, and HRQOL were based on self-reports, and the present study is a cross-sectional study. Therefore, cause-and-effect interpretations on variables cannot be established.

\section{Conclusions}

The findings demonstrate that HL, self-efficacy, social support, and health-promoting behavior are important for an elderly individual's QOL. Moreover, $21-22 \%$ of the variance in HRQOL outcomes were validated by the results obtained. However, there is still a notable proportion of unexplained variance. Additional research should be conducted to assess other predictors of HRQOL in older adults.

Author Contributions: Conceptualization, M.K.L. and J.O.; methodology, M.K.L.; software, M.K.L.; validation, J.O.; formal analysis, J.O.; investigation, J.O.; resources, M.K.L.; data curation, M.K.L.; writing一original draft preparation, M.K.L. and J.O.; writing—review and editing, M.K.L. and J.O.; visualization, J.O.; supervision, M.K.L.; project administration, J.O. All authors have read and agreed to the published version of the manuscript.

Funding: This research was funded by the National Research Foundation of Korea (NRF) grant funded by the Korea government Ministry of Science and ICT (MSIT), grant number 2020R1C1C1015358.

Conflicts of Interest: The authors declare no conflict of interest.

\section{References}

1. Statistics Korea. World and Korea Population Prospects. 2018. Available online: http://kosis.kr/eng/ statisticsList/statisticsListIndex.do (accessed on 15 October 2020).

2. Feng, Z.; Cramm, J.M.; Nieboer, A.P. Social participation is an important health behaviour for health and quality of life among chronically ill older Chinese people. BMC Geriatr. 2020, 20, 299. [CrossRef] [PubMed]

3. Kostka, T.; Jachimowicz, V. Relationship of quality of life to dispositional optimism, health locus of control and self-efficacy in older participants living in different environments. Qual. Life Res. 2010, 19, 351-361. [CrossRef] [PubMed]

4. Panagioti, M.; Skevington, S.M.; Hann, M.; Howells, K.; Blakemore, A.; Reeves, D.; Bower, P. Effect of health literacy on the quality of life of older patients with long-term conditions: A large cohort study in UK general practice. Qual. Life Res. 2018, 27, 1257-1268. [CrossRef] [PubMed]

5. Stretton, C.M.; Latham, N.K.; Carter, K.N.; Lee, A.C.; Anderson, C.S. Determinants of physical health in frail older people: The importance of self-efficacy. Clin. Rehabil. 2006, 20, 357-366. [CrossRef]

6. Rootman, I.; Gordon-El-Bihbety, D. A Vision for a Health Literate Canada; Canadian Public Health Association: Ottawa, ON, Canada, 2008.

7. Kim, Y.S.; Park, B.H.; Lee, H.Y. A study on predicting health literacy of Korean elderly using Andersen's health behavior model. J. Welf. Aged Inst. 2014, 65, 35-57. 
8. National Institute of the Korean Language. The National Literacy Survey; The National Institute of the Korean Language: Seoul, Korea, 2018.

9. Kim, S.H.; Yu, X. The mediating effect of self-efficacy on the relationship between health literacy and health status in Korean older adults: A short report. Aging Mental Health 2010, 14, 870-873. [CrossRef]

10. Boyle, P.A.; Yu, L.; Wilson, R.S.; Segawa, E.; Buchman, A.S.; Bennett, D.A. Cognitive decline impairs financial and health literacy among community-based older persons without dementia. Psychol. Aging 2013, $28,614$. [CrossRef]

11. Liu, Y.B.; Liu, L.; Li, Y.F.; Chen, Y.L. Relationship between health literacy, health-related behaviors and health status: A survey of elderly Chinese. Int. J. Environ. Res. Public Health 2015, 12, 9714-9725. [CrossRef]

12. Soones, T.N.; Lin, J.L.; Wolf, M.S.; O'Conor, R.; Martynenko, M.; Wisnivesky, J.P.; Federman, A.D. Pathways linking health literacy, health beliefs, and cognition to medication adherence in older adults with asthma. J. Allergy Clin. Immunol. 2017, 139, 804-809. [CrossRef]

13. Barlow, J.H.; Williams, B.; Wright, C. The Generalized Self-Efficacy Scale in people with arthritis. Arthritis Care Res. 1996, 9, 189-196. [CrossRef]

14. Bandura, A. Self-efficacy: Toward a unifying theory of behavioral change. Psychol. Rev. 1977, 84, 191-215. [CrossRef] [PubMed]

15. Schwarzer, R.; Jerusalem, M.; Weinman, J.; Wright, S.; Johnston, M. Measures in Health Psychology: A User's Portfolio. In Causal and Control Beliefs; Nfer-Nelson: Windsor, UK, 1995; pp. 35-37.

16. Waller, K.V.; Bates, R.C. Health locus of control and self-efficacy beliefs in a healthy elderly sample. Am. J. Health Promot. 1992, 6, 302-309. [CrossRef] [PubMed]

17. Ayalon, R.; Bachner, Y.G. Medical, social, and personal factors as correlates of quality of life among older cancer patients with permanent stoma. Eur. J. Oncol. Nurs. 2019, 38, 50-56. [CrossRef] [PubMed]

18. Lara, R.; Vázquez, M.L.; Ogallar, A.; Godoy-Izquierdo, D. Psychosocial resources for hedonic balance, life satisfaction and happiness in the elderly: A path analysis. Int. J. Environ. Res. Public Health 2020, 17, 5684. [CrossRef]

19. Aminuddin, H.B.; Jiao, N.; Jiang, Y.; Hong, J.; Wang, W. Effectiveness of smartphone-based self-management interventions on self-efficacy, self-care activities, health-related quality of life and clinical outcomes in patients with type 2 diabetes: A systematic review and meta-analysis. Int. J. Nurs. Stud. 2019, 103286, in press. [CrossRef] [PubMed]

20. Gurung, R. Coping and social support. In Health Psychology: A Cultural Approach; Thomson: Belmont, CA, USA, 2006; pp. 131-171.

21. Bélangerm, E.; Ahmedm, T.; Vafaei, M.A.; Curciom, C.L.; Phillipsm, S.P.; Zunzuneguim, M.V. Sources of social support associated with health and quality of life: A cross-sectional study among Canadian and Latin American older adults. BMJ Open 2016, 6, e011503. [CrossRef]

22. Sarla, E.; Lambrinou, E.; Galanis, P.; Kalokairinou, A.; Sourtzi, P. Factors that influence the relationship Between social support and health-related quality of life of older people living in the community. Gerontol. Geriatr. Med. 2020, 6, 2333721420911474. [CrossRef]

23. Geffen, L.N.; Kelly, G.; Morris, J.N.; Howard, E.P. Peer-to-peer support model to improve quality of life among highly vulnerable, low-income older adults in Cape Town, South Africa. BMC Geriatr. 2019, 19, 279. [CrossRef]

24. Lee, S.M. The Effects of Lifestyle of the Older Women on the Health Promotion Hehaviors and Life Satisfaction. Ph.D. Thesis, Hoseo University Asan-si, Chungcheongnam-do, Korea, 2012. in press.

25. Mofrad, Z.P.; Jahantigh, M.; Arbabisarjou, A. Health Promotion behaviors and chronic diseases of aging in the elderly people of Iranshahr-IR Iran. Glob. J. Health Sci. 2016, 8, 139. [CrossRef]

26. Buffart, L.M.; Newton, R.U.; Chinapaw, M.J.; Taaffe, D.R.; Spry, N.A.; Denham, J.W.; Joseph, D.J.; Lamb, D.S.; Brug, J.; Galvão, D.A. The effect, moderators, and mediators of resistance and aerobic exercise on health-related quality of life in older long-term survivors of prostate cancer. Cancer 2015, 121, 2821-2830. [CrossRef]

27. Kong, L.N.; Hu, P.; Yao, Y.; Zhao, Q.H. Social support as a mediator between depression and quality of life in Chinese community-dwelling older adults with chronic disease. Geriatr. Nurs. 2019, 40, 252-256. [CrossRef] [PubMed]

28. Niedermeier, M.; Herzog, S.; Kopp-Wilfling, P.; Burtscher, M.; Kopp, M. Is the effect of physical activity on quality of life in older adults mediated by social support? Gerontology 2019, 65, 375-382. [CrossRef] [PubMed] 
29. Fransen, M.P.; Von Wagner, C.; Essink-Bot, M.L. Diabetes self-management in patients with low health literacy: Ordering findings from literature in a health literacy framework. Patient Educ. Couns. 2012, 88, 44-53. [CrossRef] [PubMed]

30. Lee, E.H.; Lee, Y.W.; Moon, S.H. A structural equation model linking health literacy to self-efficacy, self-care activities, and health-related quality of life in patients with type 2 diabetes. Asian Nurs. Res. 2016, 10, 82-87. [CrossRef]

31. Lee, S.H.; Lee, K.H.; Chang, S.J. Do health literacy and self-care behaviours affect quality of life in older persons with lung cancer receiving chemotherapy? Int. J. Nurs. Pract. 2018, 24, e12691. [CrossRef]

32. Bowling, A.; Iliffe, S. Psychological approach to successful ageing predicts future quality of life in older adults. Health Qual. Life Outcomes 2011, 9, 13. [CrossRef]

33. Choi, J.S.; Kim, B.H.; Chang, S.J. Gender-specific factors influencing diabetes self-care behaviors and health-related quality of life Among older adults With Type 2 diabetes in South Korea. Res. Gerontol. Nurs. 2015, 8, 231-239. [CrossRef]

34. Kim, H.K.; Hisata, M.; Kai, I.; Lee, S.K. Social support exchange and quality of life among the Korean elderly. J. Cross Cult. Gerontol. 2000, 15, 331-347. [CrossRef]

35. Borson, S.; Scanlan, J.M.; Chen, P.; Ganguli, M. The mini-cog as a screen for dementia: Validation in a population-based sample. J. Am. Geriatr. Soc. 2003, 51, 1451-1454. [CrossRef]

36. Lee, T.W.; Kang, S.J. Development of the short form of the Korean health literacy scale for the elderly. Res. Nurs. Health 2013, 36, 524-534. [CrossRef]

37. Sherbourne, C.D.; Stewart, A.L. The MOS social support survey. Soc. Sci. Med. 1991, 32, 705-714. [CrossRef]

38. Walker, N.; Sechrist, K.; Pender, N. The Health Promoting Lifestyle Profile II Questionnaire; University of Nebraska Medical Center, Nebraska's Health Science Center: Omaha, NE, USA, 1995.

39. Ware, J.E., Jr.; Kosinski, M.; Keller, S.D. A 12-Item Short-Form Health Survey: Construction of scales and preliminary tests of reliability and validity. Med. Care 1996, 34, 220-233. [CrossRef]

40. Sygit, K.; Siedlecka-Pasierbiak, K.; Sygit, M.; Cipora, E. The Quality of Life of Seniors Hospitalized Due to Cardiovascular Diseases in Poland. Int. J. Environ. Res. Public Health 2020, 17, 3721. [CrossRef] [PubMed]

41. Lacson, E.; Xu, J.; Lin, S.F.; Dean, S.G.; Lazarus, J.M.; Hakim, R.M. A comparison of SF-36 and SF-12 composite scores and subsequent hospitalization and mortality risks in long-term dialysis patients. Clin. J. Am. Soc. Nephrol. 2010, 5, 252-260. [CrossRef] [PubMed]

42. Son, Y.J.; Yu, H.Y. Influence of health literacy on HRQoL in patients After PCI. West. J. Nurs. Res. 2016, 38, 1611-1626. [CrossRef]

43. Safeer, R.S.; Keenan, J. Health literacy: The gap between physicians and patients. Am. Fam. Phys. 2005, $72,463-468$.

44. Davis, T.C.; Wolf, M.S.; Bass, P.F., III; Thompson, J.A.; Tilson, H.H.; Neuberger, M.; Parker, R.M. Literacy and misunderstanding prescription drug labels. Ann. Intern. Med. 2006, 145, 887-894. [CrossRef]

45. Wolf, M.S.; Feinglass, J.; Thompson, J.; Baker, D.W. In search of 'low health literacy': Threshold vs. gradient effect of literacy on health status and mortality. Soc. Sci. Med. 2010, 70, 1335-1341. [CrossRef]

46. Patel, P.J.; Joel, S.; Rovena, G.; Pedireddy, S.; Saad, S.; Rachmale, R.; Shukla, M.; Deol, B.B.; Cardozo, L. Testing the utility of the newest vital sign (NVS) health literacy assessment tool in older African-American patients. Patient Educ. Couns. 2011, 85, 505-507. [CrossRef]

47. Ennis, K.; Hawthorne, K.; Frownfelter, D. How physical therapists can strategically effect health outcomes for older adults with limited health literacy. J. Geriatr. Phys. Ther. 2012, 35, 148-154. [CrossRef]

48. Zheng, M.; Jin, H.; Shi, N.; Duan, C.; Wang, D.; Yu, X.; Li, X. The relationship between health literacy and quality of life: A systematic review and meta-analysis. Health Qual. Life Outcomes 2018, 16, 201. [CrossRef]

49. Mudrak, J.; Stochl, J.; Slepicka, P.; Elavsky, S. Physical activity, self-efficacy, and quality of life in older Czech adults. Eur. J. Ageing 2016, 13, 5-14. [CrossRef]

50. Yazdi-Ravandi, S.; Taslimi, Z.; Jamshidian, N.; Saberi, H.; Shams, J.; Haghparast, A. Prediction of quality of life by Self-Efficacy, Pain Intensity and Pain Duration in Patient with Pain Disorders. Basic Clin. Neurosci. 2013, 4, 117-124.

51. Bowen, P.G.; Clay, O.J.; Lee, L.T.; Vice, J.; Ovalle, F.; Crowe, M. Associations of social support and self-efficacy with quality of life in older adults with diabetes. J. Gerontol. Nurs. 2015, 41, 21-29, quiz 30-21. [CrossRef] [PubMed] 
52. Costa, L.C.; Maher, C.G.; McAuley, J.H.; Hancock, M.J.; Smeets, R.J. Self-efficacy is more important than fear of movement in mediating the relationship between pain and disability in chronic low back pain. Eur. J. Pain. 2011, 15, 213-219. [CrossRef] [PubMed]

53. Kratz, A.L.; Molton, I.R.; Jensen, M.P.; Ehde, D.M.; Nielson, W.R. Further evaluation of the Motivational Model of Pain Self-Management: Coping with chronic pain in multiple sclerosis. Ann. Behav. Med. 2011, 41, 391-400. [CrossRef] [PubMed]

54. Kreitler, S.; Peleg, D.; Ehrenfeld, M. Stress, self-efficacy and quality of life in cancer patients. Psychooncology 2007, 16, 329-341. [CrossRef]

55. Karademas, E.C. Self-efficacy, social support and well-being: The mediating role of optimism. Pers. Individ. Dif. 2006, 40, 1281-1290. [CrossRef]

56. Han, K.; Lee, P.; Lee, S.; Park, E. Factors influencing quality of life in people with chronic illness in Korea. J. Nurs. Scholarsh. 2003, 35, 139-144. [CrossRef]

57. Afendy, A.; Kallman, J.B.; Stepanova, M.; Younoszai, Z.; Aquino, R.D.; Bianchi, G.; Marchesini, G.; Younossi, Z.M. Predictors of health-related quality of life in patients with chronic liver disease. Aliment. Pharmacol. Ther. 2009, 30, 469-476. [CrossRef]

58. Chen, Y.J.; Wang, J.K.; Liu, C.Y.; Yang, C.Y.; Chiang, Y.T.; Chen, C.W. Healthcare needs and quality of life in youths with congenital heart disease: Health-promoting behaviors as a mediator. J. Pediatr. Nurs. 2020, 50, e113-e118. [CrossRef] [PubMed]

59. De Maria, M.; Tagliabue, S.; Ausili, D.; Vellone, E.; Matarese, M. Perceived social support and health-related quality of life in older adults who have multiple chronic conditions and their caregivers: A dyadic analysis. Soc. Sci. Med. 2020, 262, 113193. [CrossRef] [PubMed]

60. Wen, Q.; Shao, Z.; Zhang, P.; Zhu, T.; Li, D.; Wang, S. Mental distress, quality of life and social support in recurrent ovarian cancer patients during active chemotherapy. Eur. J. Obstet. Gynecol. Reprod. Biol. 2017, 216, 85-91. [CrossRef] [PubMed]

61. Zhang, H.; Xiong, R.H.; Hujiken, S.; Zhang, J.J.; Zhang, X.Q. Psychological distress, family functioning, and social support in family caregivers for patients with dementia in the mainland of China. Chin. Med. J. 2013, 126, 3417-3421. [PubMed]

62. Liao, J.; Brunner, E.J. Structural and functional measures of social relationships and quality of life among older adults: Does chronic disease status matter? Qual. Life Res. 2016, 25, 153-164. [CrossRef] [PubMed]

63. Sok, S.R.; Yun, E.K. A comparison of physical health status, self-esteem, family support and health-promoting behaviours between aged living alone and living with family in Korea. J. Clin. Nurs. 2011, 20, 1606-1612. [CrossRef] [PubMed]

64. Ma, V.; Schoeneman, T.J. Individualism versus collectivism: A comparison of Kenyan and American self-concepts. Basic Appl. Soc. Psychol. 1997, 19, 261-273. [CrossRef]

65. Reinhard, S.C.; Given, B.; Petlick, N.H.; Bemis, A. Supporting family caregivers in providing care. In Patient Safety and Quality: An Evidence-Based Handbook for Nurses; Agency for Healthcare Research and Quality: Rockville, MD, USA, 2008.

66. Foottit, J.; Anderson, D. Associations between perception of wellness and health-related quality of life, comorbidities, modifiable lifestyle factors and demographics in older Australians. Australas. J. Ageing 2012, 31, 22-27. [CrossRef]

67. Ohaeri, J.U.; Awadalla, A.W.; Farah, A.A. Quality of life in people with epilepsy and their family caregivers. An Arab experience using the short version of the World Health Organization quality of life instrument. Saudi Med. J. 2009, 30, 1328-1335.

Publisher's Note: MDPI stays neutral with regard to jurisdictional claims in published maps and institutional affiliations.

(C) 2020 by the authors. Licensee MDPI, Basel, Switzerland. This article is an open access article distributed under the terms and conditions of the Creative Commons Attribution (CC BY) license (http://creativecommons.org/licenses/by/4.0/). 